\title{
Pollution characteristics of toxic metals in topsoil of small and medium-sized cities in mountainous areas of loess plateau in china-A case study of Guyuan
}

\author{
Gui Ma ${ }^{1,2}$ a Xinning $\operatorname{Han}^{1,2}$, Wenxia Zhao ${ }^{1,2}$, Jiangping $\mathrm{Cao}^{1,2}$ and Meiyuan $\mathrm{Li}^{1}$ \\ ${ }^{1}$ College of Chemistry and Chemical Engineering, Ningxia Normal University, Guyuan 756000, P. R. China \\ ${ }^{2}$ Engineering and Technology Research Centre of Liupanshan Resources, Ningxia Normal University, Guyuan 756000, P. R. China
}

\begin{abstract}
Urban soils are subjected to large number of pollutants (including toxic metals). This study investigated the urban soil environmental quality of Guyuan (a typical mountainous city in the Loess Plateau of northwestern China) by determining the concentrations of eight toxic metals $(\mathrm{Cu}, \mathrm{Zn}, \mathrm{Cd}, \mathrm{Pb}, \mathrm{Cr}, \mathrm{Ni}, \mathrm{Mn}$, and $\mathrm{Co}$ ) in urban topsoil as well as their potential sources. The toxic metal contents in the urban topsoil of Guyuan were generally less than those of other cities in northwestern China. Majority of the metals were highly concentrated in commercial and residential areas at the centre of Guyuan and the industrial region in southeastern Guyuan. The results of our study can contribute towards controlling, managing, and preventing soil pollution, as well as implementing safe layouts for the development of mountainous cities from the planning stage itself.
\end{abstract}

\section{Introduction}

As an important source and sink of urban pollutants, urban soil is crucial to the urban ecosystem [1]. Vast amounts of pollutants such as polyaromatic hydrocarbons (PAHs) and heavy metals are released into urban soil owing to rapid economic development and the corresponding growth of urban areas [2-5]. These pollutants are not only toxic, they are also persistent in the environment, and can be bioaccumulated or amplified in the soil. Thus, they are a threat to human and ecosystem health [6]. Coupled with the fact that urban soil suffers from low water and nutrient contents as well as poor structure, urban soil pollution has become a major research topic [7].

In recent decades, international research on urban topsoil has focused on the levels, spatial distributions, and sources of toxic metal pollution, as well as risk assessment [8-11], however, most of these studies were focused on megacities in either developing or developed countries $[12,13]$. Metal pollution in urban topsoil is predominantly related to the economy, level of urbanization, transportation, pollution control, and other environmental protection measures in each city [14]. Owing to significant economic growth and accelerated urbanization, coupled with a lack of scientific urban planning and attention to environmental protection, some small- and medium-sized cities exhibit more serious environmental problems than large cities [15]. However, current research regarding heavy metal pollution in the topsoil of small- and mediumsized cities is limited [14].

Guyuan is located in Ningxia Province in the Loess Plateau of Northwest China. In recent decades, it has experienced significant economic development and urban construction, particularly as part of the China Western Development Program that was initiated in the 1990s. This has led to many environmental problems; however, no previous studies have characterized the heavy metal pollution in the topsoil in this city. Therefore, in this study, to determine the level of pollution in the topsoil in Guyuan, the concentrations, spatial distributions, and potential sources of the toxic metal elements found in the Guyuan topsoil were analysed. The results obtained provide fundamental data for managers and engineers in the fields of environmental protection and environmental monitoring, among others.

\section{Materials and methods}

\subsection{Climate and population characteristics of Guyuan}

Guyuan, which is located in the northwestern Loess Plateau of China $\left(105^{\circ} 20^{\prime \prime}-106^{\circ} 58^{\prime \prime} \mathrm{E}, 35^{\circ} 14^{\prime \prime}-356^{\circ} 38^{\prime \prime} \mathrm{N}\right)$, is bordered by the Liupan Mountains to the north and south, and has an altitude of $1500-2200 \mathrm{~m}$. It is a regional central city in the southern Ningxia Hui Autonomous Region, with an urban area of $45 \mathrm{~km}^{2}$ and a total area of $10540 \mathrm{~km}^{2}$. It exhibits a continental climate that is typical of semi-arid and arid regions of the central and northern Loess Plateau. The annual average precipitation, temperature, and hours of sunshine in this city are 492.2 $\mathrm{mm}, 6.2{ }^{\circ} \mathrm{C}$, and $2518.2 \mathrm{~h}$, respectively. The annual precipitation in Guyuan has uneven spatial and temporal distributions, characterized by less precipitation during the

${ }^{\mathrm{a}}$ Corresponding author: nxsfxymg@163.com 
spring and summer, intermittent mild droughts, and more precipitation during the autumn. By the end of 2018, Guyuan had a total permanent population of $1,242,400$ (471,200 urban residents and 771,100 rural residents) and 24,000 civilian cars. In 2018, Guyuan has attained a GDP of 30.319 billion yuan, excluding price factors, with an increase of $6.6 \%$ over the previous year [16]. Specifically, the added value of primary industries was 5.782 billion yuan, representing an increase of $4.0 \%$, whereas the added values of secondary and tertiary industries were 8.456 billion yuan and 16.082 billion yuan, representing increases of $7.5 \%$ and $7.0 \%$, respectively [16].

\subsection{Sample collection and analysis}

The sampling locations in the Guyuan urban area are shown in Figure 1. A total of 66 sampling sites were randomly distributed according to a $1 \mathrm{~km}^{2}$ grid, ensuring that there was at least one sampling site in each grid. Each soil sample was composed of 3 to 5 sub-samples. The topsoil was sampled from the soil depth of 0-20 cm with a stainless steel hand auger, and sealed in polyethylene plastic bags in April, 2018 and June, 2019. During sampling, the GPS (C118, Zhichuang Corporation, Shandong, China) coordinates of each sampling site were tagged. The topsoil samples were brought back to the laboratory, and allowed to air dry for two weeks. Grinding and heavy metal content analyses were conducted after passing the dried samples through a $1 \mathrm{~mm}$ nylon mesh. We used $0.2 \mathrm{~g}$ of each sample for weighing and digestion using $\mathrm{HF}, \mathrm{HNO}_{3}$, and $\mathrm{HClO}_{4}$. Graphite furnace atomic absorption spectroscopy (WFX-130A, Ruili Corporation, Beijing, China) was used to measure the total concentrations of copper, lead, zinc, chromium, cadmium, cobalt, manganese, and nickel in each sample. Sample quality was controlled using a standard sample (GSD-12, GSS1) and a $15 \%$ duplicate sample. The errors of the elemental analyses were controlled within $5 \%$.

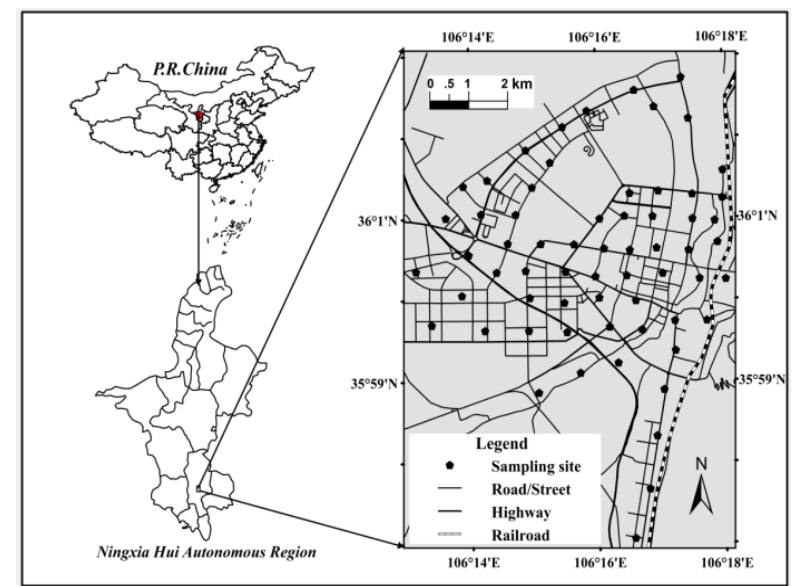

Fig1. Map of the topsoil sampling sites in Guyuan City, China.

\subsection{Heavy metal enrichment factor}

The extent of heavy metal enrichment was assessed using the enrichment factor (EF) as previously described by as follows:

$$
\mathrm{EF}=\left(c_{i} / c_{r}\right)_{\mathrm{s}} /\left(c_{i} / c_{r}\right)_{\mathrm{b}}
$$

where the subscripts $b$ and $s$ indicate the background and sample, respectively. Furthermore, $\mathrm{c}_{\mathrm{i}} / \mathrm{c}_{\mathrm{r}}$ denotes the ratio of the measured toxic metal content, $i$, to that of a reference element, $r$, the background heavy metal elemental values refer to the surface soil background values for Ningxia [17]. Given its environmental stability, $\mathrm{Al}$ was chosen as the reference element $\left(\mathrm{Al}_{2} \mathrm{O}_{3}\right.$, with a variation coefficient of 0.05) [18]. The average value of the measured $\mathrm{Al}$ data was used as the background value. An EF value greater than 10 indicates that anthropogenic emissions are the dominant source of heavy metals, while an $\mathrm{EF}$ value close to 1 indicates a predominantly natural source [19]. Further details on EF classification can be found in previous studies [20].

\subsection{Multivariate statistical analysis}

Geographic Information Systems (GIS) is suitable for determining the spatial distribution of regional pollution, whereas multivariate statistical analysis (MSA) is only suitable for describing the overall pollution status of the study area. Therefore, researchers often combine GIS and MSA for soil pollution source analyses [21]. MSA generally includes principal component analysis (PCA), correlation coefficient analysis (CCA), and cluster analysis (CA), all of which can be used to identify heavy metal sources in urban topsoil [22], soil [23], and dust $[11,15]$. CCA reflects the source similarities of heavy metals through linear correlations between heavy metal data from Pearson product moment analyses [24], and is widely used in research on environmental pollutants [25]. To analyze the measured data, PCA, which is often used to determine the sources of environmental pollutants [26], was reduced from multiple indicators to several comprehensive indicators [27]. In this study, the KaiserMeyer-Olkin (KMO) Measure of Sampling Adequacy $(0.782)$ and Bartlett test value $(\mathrm{P}<0.001)$ showed that the measured metal concentrations observed in the Guyuan topsoil were suitable for PCA [12]. Finally, CA can reveal the source similarities of different pollutants, and is typically employed to verify the PCA results [28].

\section{RESULTS AND DISCUSSION}

\subsection{Heavy metal concentrations in topsoil}

The heavy metal contents of the urban topsoil samples from Guyuan are listed in Table 1. The mean heavy metal concentrations ranked in decreasing order were as follows: $\mathrm{Mn}>\mathrm{Cr}>\mathrm{Zn}>\mathrm{Ni}>\mathrm{Cu}>\mathrm{Pb}>\mathrm{Co}>\mathrm{Cd}$. In all the samples, $\mathrm{Cu}, \mathrm{Zn}, \mathrm{Pb}$, and $\mathrm{Cr}$ contents were 0.27-2.43, 0.53-1.58, $0.52-1.83$, and $0.54-3.49$ times the corresponding background values, respectively. Co contents in most specimens (95\%) were lower than the corresponding background values; however, in $64 \%, 78 \%, 56 \%$, and $62 \%$ of the samples, $\mathrm{Cu}, \mathrm{Zn}, \mathrm{Cr}$, and $\mathrm{Pb}$, respectively, had higher concentrations than their corresponding background data for the urban topsoil in Guyuan City $\left(\mathrm{mg} \cdot \mathrm{kg}^{-1}\right)$ values. The variation coefficients of the heavy 
metal elements in the Guyuan topsoil were ranked in decreasing order as follows: $\mathrm{Pb}>\mathrm{Cd}>\mathrm{Cu}>\mathrm{Ni}>\mathrm{Zn}>$ $\mathrm{Cr}>\mathrm{Mn}>\mathrm{Co}$. Among these, the variation coefficients of $\mathrm{Pb}, \mathrm{Cd}, \mathrm{Cu}, \mathrm{Ni}, \mathrm{Zn}$, and $\mathrm{Cr}$ were all between $20 \%$ and $<$ $50 \%$, indicating moderate content changes in these soil samples. Moreover, the coefficients of variation of $\mathrm{Mn}$ and Co were $<20 \%$, indicating that their content variations were relatively low. The kurtosis values of $\mathrm{Pb}$, $\mathrm{Cr}, \mathrm{Ni}$, and $\mathrm{Co}$ in the topsoil specimens were all positive, showing steeper metal distributions than normal. Furthermore, $\mathrm{Pb}, \mathrm{Ni}, \mathrm{Cd}$, and $\mathrm{Cu}$ were skewed towards relatively low concentrations. Different population values, methods of production, and lifestyle activities among cities lead to different types of heavy metal pollution [14]. The heavy metal contents in the urban topsoil of Guyuan were generally less than those of other cities in northwestern China (Table 1). This may be due to the relatively small scale of Guyuan City, the relatively slow economic development, and the little impact of urban production and daily activities on urban soil.

\subsection{Heavy metal enrichments in topsoil}

The EF values of heavy metal elements in the topsoil samples are shown in Figure 2. EFs of 0.3-2.8, 0.5-1.8, $0.1-2.5,0.4-1.9,0.5-2.2,0.3-2.0,0.5-1.3$, and $0.5-1.2$ were determined for $\mathrm{Cu}, \mathrm{Zn}, \mathrm{Cd}, \mathrm{Pb}, \mathrm{Cr}, \mathrm{Ni}, \mathrm{Mn}$, and $\mathrm{Co}$, respectively, with the mean value of $\mathrm{Cu}(1.3)>\mathrm{Pb}(1.3)>$ $\mathrm{Cr}(1.2)>\mathrm{Zn}(1.1)>\mathrm{Cd}(1.0)>\mathrm{Mn}(0.9)=\mathrm{Co}(0.9)>\mathrm{Ni}$ (0.8). The average EF values of all metals were less than
2 , indicating their deficiencies relative to the minimum enrichment value. EF values of 2-5 was obtained for $2 \%$ of $\mathrm{Cd}$ specimens and $10 \%$ of $\mathrm{Cu}$ samples, suggesting that $\mathrm{Cu}$ and $\mathrm{Cd}$ were moderately enriched at some sampling points. The EF results showed that $\mathrm{Pb}, \mathrm{Cr}, \mathrm{Zn}, \mathrm{Ni}, \mathrm{Mn}$, and $\mathrm{Co}$ in the Guyuan topsoil originated from natural sources, whereas $\mathrm{Cu}$ and $\mathrm{Cd}$ partly originated from anthropogenic sources. the figure as close as possible after the point where it is first referenced in the text. If there is a large number of figures and tables it might be necessary to place some before their text citation. If a figure or table is too large to fit into one column, it can be centred across both columns at the top or the bottom of the page.

\subsection{Spatial distribution characteristics}

The Kriging interpolation method, which is derived from the regionalized variable theory, is often adopted to measure the spatial distribution characteristics of pollutants in soil [36]. In this study, it was employed to determine the spatial distributions of eight toxic metal elements in the topsoil samples from Guyuan, and the results obtained are plotted in Figure 3. The heavy metal contents were higher in the centre and southeastern sections of Guyuan (more than 1.5 times the background value). These two high-concentration areas are located near the Liupanshan thermal power plant and the Nanhetan Industrial Park, respectively.

The sources of heavy metals can be inferred from

Table 1 Heavy metal concentrations and statistical data for the urban topsoil in Guyuan City (mg $\cdot \mathrm{kg}-1)$

\begin{tabular}{ccccccccc}
\hline & $\mathrm{Cu}$ & $\mathrm{Zn}$ & $\mathrm{Cd}$ & $\mathrm{Pb}$ & $\mathrm{Cr}$ & $\mathrm{Ni}$ & $\mathrm{Mn}$ & $\mathrm{Co}$ \\
\hline Mean & 27.69 & 62.35 & 0.11 & 25.04 & 69.85 & 30.45 & 456.47 & 9.83 \\
Median & 25.88 & 61.17 & 0.10 & 23.81 & 68.30 & 29.96 & 466.88 & 9.74 \\
Minimum & 6.01 & 31.28 & 0.00 & 0.12 & 31.68 & 9.77 & 274.32 & 6.57 \\
Maximum & 53.78 & 92.91 & 0.23 & 71.92 & 111.32 & 75.85 & 561.49 & 11.83 \\
SD & 12.14 & 15.19 & 0.05 & 12.24 & 14.60 & 9.21 & 75.75 & 0.95 \\
CV\% & 43.84 & 24.36 & 47.01 & 48.90 & 20.90 & 30.26 & 16.60 & 9.66 \\
Background values [17] & 22.1 & 58.8 & 0.112 & 20.6 & 60.6 & 36.6 & 524 & 11.6 \\
Xi, an [29] & 35.41 & 95.91 & $\mathrm{NA}$ & 39.23 & 79.86 & 32.30 & NA & 18.50 \\
Lanzhou[30] & 85.68 & 227.4 & 0.84 & 96.36 & 94.78 & NA & NA & NA \\
Xining [31] & 20.85 & 48.60 & NA & 34.85 & 200.7 & NA & NA & 16.0 \\
Baoji [20] & 24.20 & 221.0 & 0.94 & 18.3 & 34.6 & 31.6 & 449 & NA \\
Baiyin[32] & 167.8 & 593.4 & 9.57 & 331.2 & NA & NA & 620.39 & NA \\
Urumqi [33] & 44.03 & 168.7 & NA & 55.17 & 117.1 & NA & NA & NA \\
Jinchang [34] & 44.11 & 56.23 & 0.10 & 18.55 & NA & 35.05 & NA & NA \\
Changji [35] & 65.99 & 221.5 & NA & 7.52 & 52.18 & NA & NA & NA \\
\hline
\end{tabular}




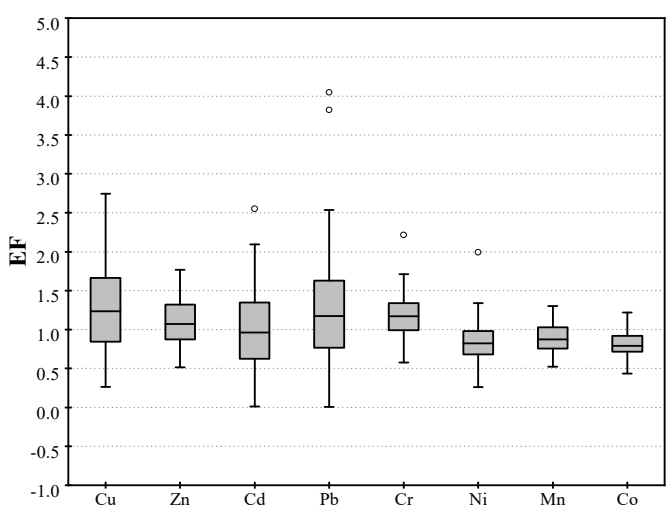

Fig2. EF values for eight heavy metals in the topsoil in Guyuan City (median, min-max values, and interquartile ranges, $\circ$ represents extreme outlier).

their spatial distributions. The spatial distributions showed that $\mathrm{Cu}, \mathrm{Zn}$, and $\mathrm{Cd}$ contents were high in the northeastern, southeastern, and central sections of the city. The thermal power plant is located in the northeastern section, the southeastern section hosts an industrial park that includes cement and building material plants, and the central section includes economic, residential, and commercial centres with high traffic and a dense population. The spatial distributions of $\mathrm{Pb}$ and $\mathrm{Ni}$ decreased from the city centre to the outskirts, indicating the same type of metal pollution source. The similar spatial distribution patterns of $\mathrm{Mn}$ and $\mathrm{Co}$ exhibited decreases from the northwest to the southeastern parts of the region. The northwestern region is a new urban area that was composed of agricultural land and villages prior to 2009. Additionally, $\mathrm{Mn}$ and Co contents had non-significant differences relative to their corresponding background values, indicating that $\mathrm{Mn}$ and Co possibly originated from the soil itself.

\subsection{Heavy metal source analysis}

MSA was employed to analyze the heavy metal sources in the urban Guyuan topsoil. The heavy metal concentration data from the PCA showed that there were three factors with characteristic values $>1$ that contributed $85.08 \%$ of the total variance (Table 3 ). PC1 explained $37.75 \%$ of the total variance, in which $\mathrm{Cu}, \mathrm{Cd}, \mathrm{Zn}$, and $\mathrm{Cr}$ had higher positive and negative loads $(>0.8)$ and exhibited clear positive correlations $(\mathrm{P}<0.01)$ (Table 3$)$; thus, these metals were treated as belonging to the same cluster during the $\mathrm{CA}$ (Figure 4). Moreover, the variation coefficients of $\mathrm{Cu}, \mathrm{Cd}, \mathrm{Zn}$, and $\mathrm{Cr}$ were above $20 \%$, but less than $50 \%$ (Table 1), and their heavy metal contents varied greatly between different sampling sites

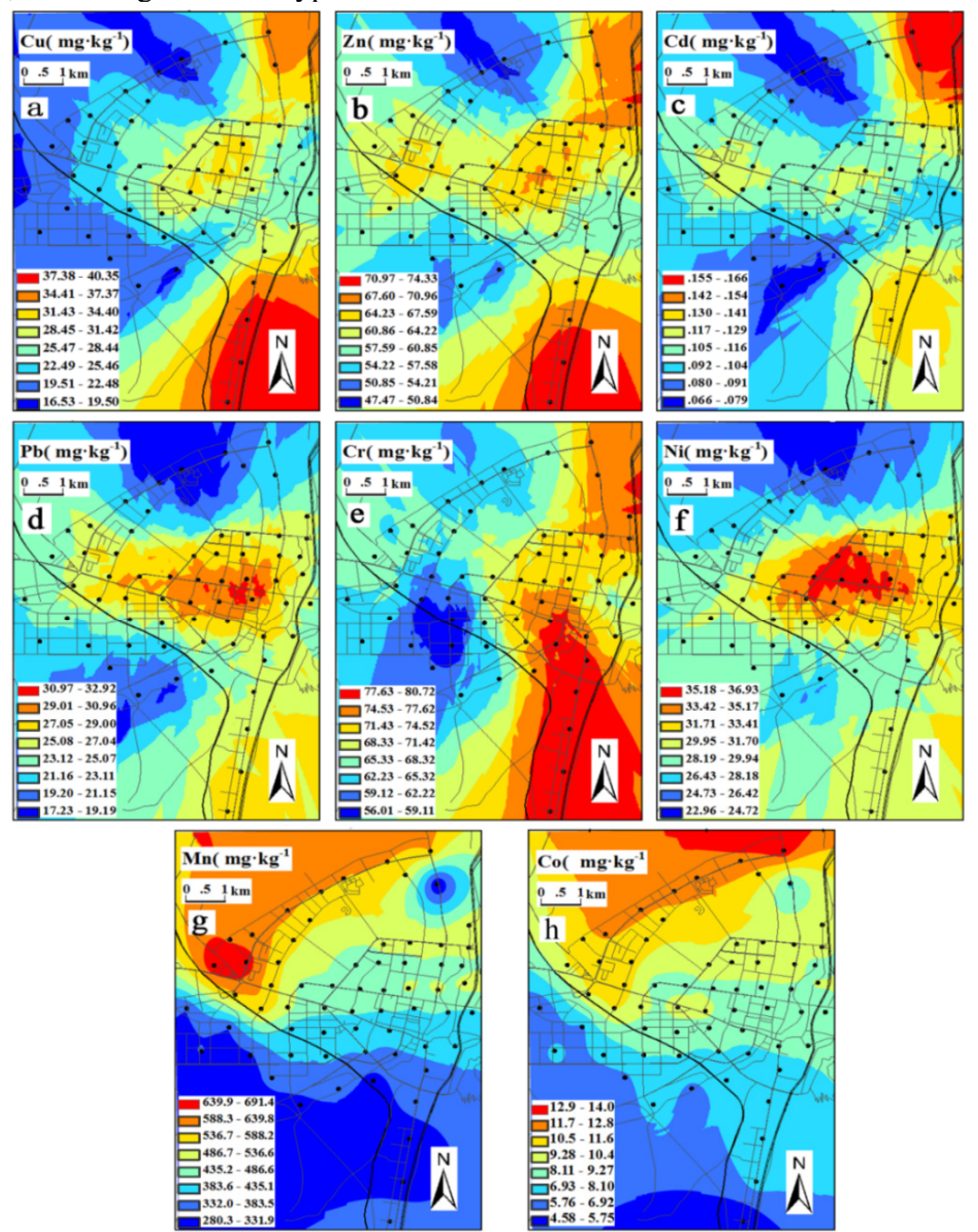

Fig3. Spatial distributions of eight toxic metal elements measured in the topsoil of Guyuan: (a) $\mathrm{Cu}$, (b) $\mathrm{Zn}$, (c) $\mathrm{Cd}$, (d) $\mathrm{Pb}$, (e) $\mathrm{Cr}$, (f) $\mathrm{Ni},(\mathrm{g}) \mathrm{Mn}$, and (h) Co. 
Table 2 Correlation matrix for heavy metal contents in urban topsoil.

\begin{tabular}{lllllllll}
\hline & $\mathrm{Cu}$ & $\mathrm{Zn}$ & $\mathrm{Cd}$ & $\mathrm{Pb}$ & $\mathrm{Cr}$ & $\mathrm{Ni}$ & $\mathrm{Mn}$ & $\mathrm{Co}$ \\
\hline $\mathrm{Cu}$ & & 0.000 & 0.000 & 0.000 & 0.000 & 0.001 & 0.686 & 0.997 \\
$\mathrm{Zn}$ & $0.880^{*}$ & & 0.000 & 0.000 & 0.000 & 0.000 & 0.969 & 0.959 \\
$\mathrm{Cd}$ & $0.770^{*}$ & $0.853^{*}$ & & 0.000 & 0.000 & 0.003 & 0.721 & 0.328 \\
$\mathrm{~Pb}$ & $0.470^{* *}$ & $0.611^{*}$ & $0.626^{*}$ & & 0.250 & 0.000 & 0.270 & 0.340 \\
$\mathrm{Cr}$ & $0.572^{* *}$ & $0.639^{*}$ & $0.620^{*}$ & 0.145 & & 0.323 & 0.419 & 0.477 \\
$\mathrm{Ni}$ & $0.420^{* *}$ & $0.422^{*}$ & $0.369^{*}$ & $0.521^{*}$ & 0.125 & & 0.783 & 0.339 \\
$\mathrm{Mn}$ & -0.051 & -0.005 & 0.045 & 0.139 & -0.102 & -0.035 & & 0.000
\end{tabular}

Right upper and left lower halves indicate the significance levels and the correlation coefficients, respectively.

** Correlation at the 0.01 level is significant.

compared with other metals, indicating that they are influenced by anthropogenic factors. The $\mathrm{Cu}$ content was $0.3-2.4$ times its background value and had an EF of $0.3-$ 2.8 , suggesting that its concentration is influenced by both human activities and natural factors. Owing to their corrosion resistance and high strength, $\mathrm{Cu}$ alloys are often used to make mechanical parts [24]. as well as automobile radiators [37]. High $\mathrm{Cr}$ concentrations have been observed at the sampling sites close to the thermal power plant [24], indicating a dominant industrial emission source [38]. Zinc mainly originates from the corrosion of zinccontaining automobile devices and automobile tire wear [15]. Moreover, areas with high contents of $\mathrm{Cu}, \mathrm{Zn}, \mathrm{Cd}$, and $\mathrm{Cr}$ were all located in the northeastern, southeastern, and central sections of Guyuan (Figure 3), which are linked to a coal plant, an industrial park, and the commercial and residential centres of the city, respectively. Thus, in the urban topsoil in Guyuan, these metals are likely derived from both natural sources and emissions related to traffic, fossil fuel combustion, and industrial activities.

PC2 explained $24.05 \%$ of the total variance. $\mathrm{Pb}$ and $\mathrm{Ni}$ exhibited clear positive correlations $(\mathrm{P}<0.01)$ with high loading factors (Table 3 ); therefore, they were assigned to the same CA cluster (Figure 4), indicating that they both had a similar source in Guyuan. In the prosperous commercial centre and city centre, $\mathrm{Pb}$ and $\mathrm{Ni}$ showed a similar spatial distribution, and their concentrations in the topsoil of Guyuan were high, indicating a traffic emission source. Previous studies have shown that traffic emissions are the dominant cause of $\mathrm{Pb}$ pollution in topsoil in different cities $[37,39,40]$, while coal combustion can also increase the $\mathrm{Pb}$ content in surface soils [13]. Moreover, $\mathrm{Pb}$ in the surface coverings of urban facilities and buildings can also be released as urban dust that eventually settles in the soil [39]. The main sources of Ni pollution are traffic emissions and brake wear [41]. Thus, by combining the concentration and $\mathrm{EF}$ results for $\mathrm{Pb}$ and $\mathrm{Ni}$ in the topsoil samples, these two metals could be mainly derived from natural sources, with minor contributions from traffic emissions and buildings.

PC3 was dominantly loaded by $\mathrm{Mn}$ and $\mathrm{Co}$, and explained $23.28 \%$ of the total variance (Table 4 ). These
Table 3 Load values of PCA factors of toxic metals in urban Topsoil.

\begin{tabular}{|c|c|c|c|c|}
\hline \multirow{2}{*}{ Element } & \multicolumn{3}{|c|}{ Component } & \multirow{2}{*}{$\begin{array}{l}\text { Commo } \\
\text { nalities }\end{array}$} \\
\hline & 1 & 2 & 3 & \\
\hline $\mathrm{Cr}$ & 0.883 & $\begin{array}{l}- \\
0.109\end{array}$ & $\begin{array}{l}- \\
0.146\end{array}$ & 0.815 \\
\hline $\mathrm{Zn}$ & 0.861 & 0.015 & 0.419 & 0.918 \\
\hline $\mathrm{Cd}$ & 0.836 & 0.115 & 0.389 & 0.863 \\
\hline $\mathrm{Cu}$ & 0.824 & $\overline{0} .025$ & 0.367 & 0.777 \\
\hline Co & 0.021 & 0.968 & $\overline{0} 030$ & 0.814 \\
\hline $\mathrm{Mn}$ & $\overline{0} .047$ & 0.957 & 0.039 & 0.763 \\
\hline $\mathrm{Ni}$ & 0.124 & 0.128 & 0.855 & 0.919 \\
\hline $\mathrm{Pb}$ & 0.319 & 0.171 & 0.803 & 0.938 \\
\hline Eigenvalue & 3.02 & 1.92 & 1.86 & \\
\hline $\begin{array}{l}\% \text { of variance } \\
\text { explained }\end{array}$ & 37.75 & 24.05 & 23.28 & \\
\hline $\begin{array}{ll}\% & \text { of } \\
\text { cumulative }\end{array}$ & 37.75 & 61.80 & 85.08 & \\
\hline
\end{tabular}

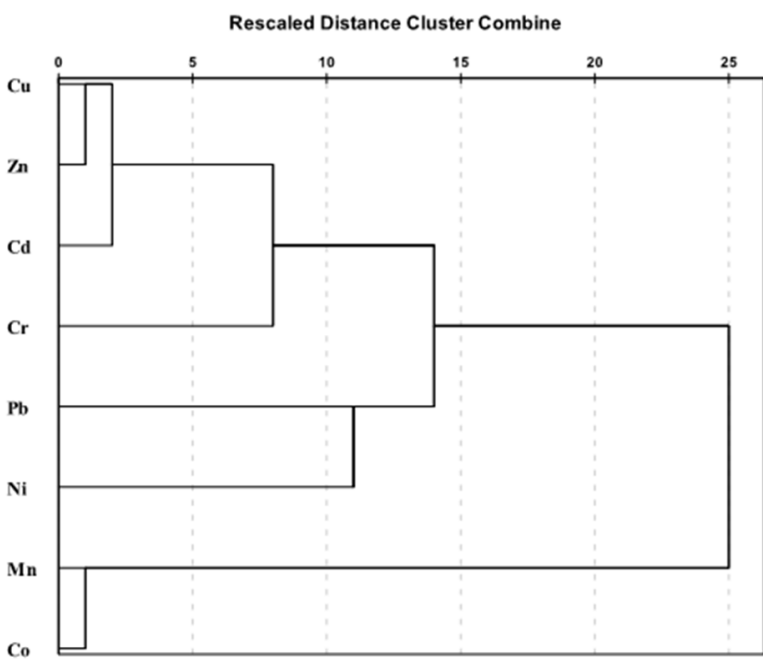

Fig4. CA results for heavy metals in urban topsoil 
two elements had no correlations with other heavy metals, but had a significant positive correlation $(\mathrm{P}<0.01)$ between themselves (Table 2). Thus, they were grouped together for the CA (Figure 3). The CV analysis of Mn and Co shows a minor influence from human factors on their concentration and distribution. Reportedly, $\mathrm{Mn}$ in

the topsoil is mainly derived from the parent soil [37]. Co and $\mathrm{Mn}$ concentrations decreased from northwest to southeast, and were highest in the new urban region located in the northwestern part of the city; however, the $\mathrm{Mn}$ and Co contents in the topsoil samples were slightly lower than their background values. Therefore, $\mathrm{Mn}$ and Co in the topsoil of Guyuan possibly originated primarily from the natural weathering and corrosion of the soil itself.

\section{Conclusion}

After analysis, the average concentrations of $\mathrm{Cu}, \mathrm{Zn}, \mathrm{Cd}$, $\mathrm{Pb}, \mathrm{Cr}, \mathrm{Ni}, \mathrm{Mn}$, and $\mathrm{Co}$ in the urban topsoil of Guyuan City were found to be $27.69,62.35,0.11,25.04,69.85,30.45$, 456.47 , and $9.83 \mathrm{mg} \cdot \mathrm{kg}^{-1}$, respectively. Generally, the degree of enrichment was very low for all the heavy metals, and only $10 \%$ and $2 \%$ of soil samples had EF values between 2 and 5 for $\mathrm{Cu}$ and $\mathrm{Cd}$, respectively, indicating moderate enrichment of $\mathrm{Cu}$ and $\mathrm{Cd}$ in some regions of Guyuan. The areas with high concentrations of $\mathrm{Cu}, \mathrm{Zn}$, and $\mathrm{Cd}$ were those located in the northeastern, southeastern, and central sections of the city. $\mathrm{Pb}$ and $\mathrm{Ni}$ exhibited very similar spatial distributions, with high concentrations in the central section of Guyuan. Mn and Co also exhibited similar spatial distributions, with concentrations decreasing from northwest to southeast. CCA, PCA, and CA analyses divided the eight heavy metals found in the topsoil of Guyuan City into three clusters according to their sources. $\mathrm{Cu}, \mathrm{Zn}, \mathrm{Cr}$, and $\mathrm{Cd}$ were derived from both natural sources and emissions from traffic and fossil fuel combustion; $\mathrm{Pb}$ and $\mathrm{Ni}$ are derived mainly from natural sources and partly from traffic emissions and construction; and $\mathrm{Mn}$ and Co only originated from the soil itself. Therefore, in follow-up studies, researchers should pay attention to the form of the heavy metals so as to obtain basic data regarding their migration in the soil, and to provide a reliable theoretical basis for soil governance and remediation.

\section{Acknowledgments}

The authors gratefully acknowledge the financial support of the National Natural Science Foundation of China (21561027), Natural Science Foundation of Ningxia (No.2020AAC03269), Ningxia Autonomous Region Higher School Scientific Research Program (Grant NGY2018-117), the Scientific research project of Ningxia Normal University (Grant NXSFZDC1805), the National Undergraduate Innovation and Entrepreneurship Training Program (201910753002), the funding from the Ningxia Normal University Liupanshan Resource Engineering Technology Research Centre (Grant HG19-02). The authors would also like to thank the editor and reviewers for their assistance with the manuscript.

\section{References}

1. H.B. Cao, S.H. Chao, L. Qiao, Y. Jiang, X. Zeng, X. Fan, Sci. Total. Environ. 575, 692 (2017)

2. M. Saeedi, L.Y. Li, M. Salmanzadeh, J. Hazard. Mater. 227, 9 (2012)

3. B.P. Yang, L.L. Zhou, N.D. Xue, Sci. Total. Environ. 443, 31 (2013)

4. C. Peng, M.E. Wang, W.P. Chen, J. Environ. Sci. 53, 99 (2017)

5. M.X. Zhang, X.W. Lu, D.Q. Shi, H.W. Pan, J. Arid. Land. 10, 653 (2018)

6. Tang J, Zhang J, Ren L, J. Gao, L. Luo, Y. Yang, Q.H. Peng, H. Huang, A.W. Chen, J. Environ. Manage. 242, 121 (2019)

7. K.G. Tiller. Aust. J. Soil Res. 30, 937 (1992)

8. N.S. Yuswir, S.M. Praveena, A.Z. Aris, S.N. Ismail, Z. Hashim, Bull. Environ. Contam. Toxicol. 95, 80 (2015)

9. D.X. Liu, J.H. Ma, Y.L. Sun, Y.M. Li, Catena, 139, 53 (2016)

10. D.Y. Hou, F.S. Li, Land. Degrada. Dev. 28, 2315 (2017)

11. H.Y. Pan, X.W. Lu, K, Lei, Sci. Total Environ. 609, 1361 (2017)

12. G.L. Yuan, T.H. Sun, P. Han, J. Li, X.X. Lang, J. Geochem. Explor. 47, 40 (2014)

13. X.D, Chen, X.W. Lu, Ecotox. Environ. Safe. 51, 153 (2018)

14. X.F. Han, X.W. Lu, Arch. Environ. Prot. 43, 10 (2017)

15. X.W. Lu, L.J. Wang, L.Y. Li, K. Lei, L. Huang, D. Kang, J. Hazard. Mater. 173, 744 (2010)

16. Guyuan Municipal Bureau of Statistics, Guyuan statistical year book in 2018. (Guyuan, China, 2019)

17. Y.Q. Wang, Y.R. Bai, J.Y. Wang, Environment Science, 37, 710 (2016)

18. Y.X. Jiang, S.H. Chao, J.W. Liu, Y. Yang, Y.J. Chen, A.C. Zhang, H.B. Cao, Chemosphere, 168, 1658 (2017)

19. Y.G. Han, P.X. Du, J. Cao, E.S. Posmentier, Sci. Total Environ. 355, 176 (2006)

20. J. Zhang, J. Dong, Q.F. Liang, Y.N. Geng, W.K. Wang, Z.F. Wang, J. Arid Land Res. Env. 36, 100 (2018)

21. B. Dong, R.Z. Zhang, Y.D. Gan, L.Q. Cai, A. Freidenreich, K.P. Wang, T.W. Guo, H.B. Wang, Sci. Total. Environ. 651, 3127 (2016)

22. J. Zhou, K. Feng, Z.P. Pei, F. Meng, J. Sun, Ecotoxicology, 25, 380 (2016)

23. J.S. Lv, Y. Liu, Z.L. Zhang, J.R. Dai, B.D. Dai, Y.C. Zhu, J. Soils Sediments, 15, 163 (2016)

24. Y.L. Jin, D. O'Connor, Y.S. Ok, D.C.W. Tsang, A. Liu, D.Y. Hou, Environ. Int. 124, 320 (2019)

25. X.Y. Li, L.J. Liu, Y.G. Wang, G.P. Luo, X. Chen, X.L. Yang, M.H. Hall, R.C. Guo, H.J. Wang, J.H. Cui, X.Y. He, Geoderma, 192, 50 (2012) 
26. A. Facchinelli, E. Sacchi, L. Mallen, Environ. Pollut. 114, 313 (2001)

27. H. Chen, X.W. Lu, L.Y. Li, T.N. Gao, Y.Y. Chang, Sci. Total Environ. 484, 27 (2014)

28. D.Y. Hou, D. O'Connor, P. Nathanai, L. Tian, Y. Ma, Environ. Pollut. 231, 1188 (2017)

29. X.D. Chen, X.W. Lu, Chin. J. Soil Sci. 48, 961 (2017)

30. B. Wang, D.S. Xia, Y. Yu, J. JIA, S.J. XU, Chin. Sci. Bull. 57, 3078 (2012)

31. R. Yang, X.P. Li, J.W. Wang, Q. Xu, T. Yang, Chin. J. Ecol. 35, 1532 (2016)

32. C.L. Li, W.H. Liu, Geophys. Geochem. Explor. 36, 1014 (2016)

33. Y.Y. Liu, M. Liu, H.F. Liu, Arid Land Geography, 30, 552 (2007)

34. X.N. Hu, Z.R. Nan, X.W. Liu, J. Arid Land Res. Env. 25, 180 (2011)

35. H.F. Liu, Env. Protec. Xinjiang, 29, 6 (2007)

36. M.A. Oliver, R. Webster, Int. J. Geogr. Inf. Syst. 4, 313 (1990)

37. Z.P. Yang, W.X. Lu, Y.Q. Long, X.H. Bao, Q.C. Yang, Chin. J. Geochem. Explor. 108, 27 (2011)

38. C.S. Lee, X.D. Li, W.Z. Shi, Sci. Total Environ. 356, 45 (2006)

39. X.D. Chen, X.W. Lu, G. Yang, Catena, 2012, 98:7378. 98, 73 (2012)

40. Zhang Y, Cao S, Xu X, M.X. Chen, D. Wang, D.H. Guan, C.Y. Wang, X. Wang, B.W. Dong, H. Huang, N. Zhao, L. Jin, Y.N. Bai, X.L. Duan, Q. Liu, Y.W. Zhang, Environ. Monit. Assess. 180, 1 (2016)

41. T.T. Duong, B.K. Lee, J. Environ. Manage. 92, 554 (2011) 